\title{
Creating a gold standard surgical procedure: the development and implementation of TVT
}

\author{
Ulf Ulmsten Memorial Lecture 2014
}

\author{
Carl Gustaf Nilsson
}

Received: 21 December 2014 / Accepted: 21 December 2014 / Published online: 3 March 2015

(C) The International Urogynecological Association 2015

The last two decades have witnessed a launch of new surgical procedures, utilizing kits and synthetic materials, at a pace not formerly seen. Some launches have been preceded by thorough clinical documentation and others not. Any innovation, be it a theory or a treatment concept, is only fantasy until it has been tested and clinically documented.

Within the field of surgical management of female stress urinary incontinence the presentation of the mid-urethral theory (a part of the integral theory [1]) implied a paradigm shift of understanding the mechanism of stress incontinence. The theory relied on discoveries and ideas presented between the 1950 s and the 1980 s by several clinicians such as Axel Ingelman-Sundberg [2], Robert F. Zacharin [3, 4], and Ulf Ulmsten [5-7] just to mention a few. The theory was put into practice by a team led by Professor Ulf Ulmsten by developing a new minimally invasive, ambulatory, standardized surgical procedure to be named the tension-free vaginal tape (TVT) at the time of launch in Europe at the end of 1997 and in the USA at the end of 1998.

Several modifications of a procedure were tested before arriving at the final one, which included the use of a monofilament polypropylene tape with a mesh structure and a pore size of $>$ $75 \mu \mathrm{m}$. Once the procedure was finalized, the first prospective clinical trial was conducted at the Department of Obstetrics and Gynecology of the University Hospital of Uppsala, Sweden, the chairman of which was Professor Ulmsten. The trial included 75 primary cases of stress urinary incontinence and were followed for 24 months. The results published in 1996 were very encouraging [8] and prompted further prospective clinical trials conducted in normal clinical settings. At this stage it was decided to follow the same study protocol in all the trials to come.

C. G. Nilsson $(\bowtie)$

Department of Obstetrics \& Gynecology, Helsinki University, POB 140, 00029 HUS Helsinki, Finland

e-mail: carl.nilsson@hus.fi
The pre- and postoperative evaluations were to include urodynamic testing, a cough stress test, a 24-h pad weighing test, a 2-day voiding diary, residual urine measurement, urine analysis, pelvic examination, and as a quality of life measure a visual analog scale (VAS) on the bother caused by urinary symptoms. It was also decided on the criteria of cure and improvement. To be regarded cured a patient should have a negative stress test and negative pad test, be continent in postoperative urodynamics, and score less than 10 on the VAS, where 0 represents no urinary problems whatsoever and 100 unbearable urinary symptoms. Improvement required a negative stress test, a significant reduction of leakage on the 24-h pad test, and $\mathrm{a} \geq 70 \%$ improvement of the individual VAS score. All other cases were regarded as failures.

A multicenter trial including six clinics in Finland and Sweden enrolled 130 primary cases of stress incontinence, who were followed for a minimum of 12 months, showed the same high rate of success as the initial trial. This study was published in 1998 [9], but the results were available to the investigators at the beginning of the year before. The results of trials with a followup of 4 years on women suffering from recurrent stress incontinence, intrinsic sphincter deficiency, and mixed urinary incontinence were published in 2001, once again with excellent cure rates [10-12]. Already in the year 2000 5-year follow-up results were available and published in June 2001 showing an overall cure rate of $85 \%$ according to the abovementioned criteria [13] (Table 1). Two independent studies with a 3-year follow-up were published in 1999 [14, 15] revealing the same high success rates as the earlier studies. Today we have the results of a 17-year follow-up period on the performance of the TVT procedure, which shows that no decline in cure rate develops through the years and that no late onset problems occur with the polypropylene tape used in these by now rather elderly women [16].

The most common complication of the traditional incontinence operations has been persistent or recurrent stress incontinence and for the most invasive procedures all the 
Table 1 Number of patients, time of follow-up, and cure rate in early clinical trials with the TVT procedure

\begin{tabular}{llccc}
\hline Patient group & & No. of pat. & Follow-up (months) & Cure rate \\
\hline Primary cases & Ulmsten et al. (1996), first prospective trial & 75 & 24 & $84 \%$ \\
Primary cases & Ulmsten et al. (1998), first multicenter trial & 131 & 12 & $91 \%$ \\
Unselected patients & Nilsson et al. (2001) & 161 & 24 & $87 \%$ \\
Mixed incontinence & Rezapour et al. (2001) & 80 & 48 & $85 \%$ \\
ISD cases & Rezapour et al. (2001) & 49 & 48 & $74 \%$ \\
Recurrent cases & Kuuva et al. (2003) & 51 & 24 & $80 \%$ \\
Primary cases & Nilsson et al. (2001), 5 years follow-up & 90 & 60 & $85 \%$ \\
\hline
\end{tabular}

$I S D$ intrinsic sphincter deficiency

complications associated with major surgery. The minimal invasiveness of the TVT procedure and the idea of performing the operation under local anesthesia was aimed at reducing the risk of complications. Utilizing local anesthesia allowed an intraoperative cough stress test to be performed, the purpose of which was explicitly to avoid postoperative voiding problems. Training was thought to be a key to success of performance of the operation and the procedure was therefore carefully standardized to facilitate training.

An excellent opportunity to introduce the TVT procedure in Finland through a systematic training program including all clinics in the country, which performed incontinence surgery, was captured as one of the participants in the clinical development of the TVT operation was responsible for incontinence care in the largest University Hospital in Finland. A representative of every hospital surgically treating stress incontinence was invited to the University Hospital in Helsinki to participate in a training program, which included theoretical training (the importance of focusing on the mid-urethra and not the bladder neck), surgical training, and a follow-up program. Depending upon the earlier experience of the invited surgeons each doctor had to attend two to eight TVT operations, assist in two to four TVT operations, and finally perform two to three TVT operations under supervision. A certificate to perform the TVT operation on their own was awarded to those who successfully participated in the training. A deal with the provider of the TVT kit in Finland was made that only certified surgeons could obtain the TVT kits for clinical use.

Table 2 Rate of complications in a nationwide registry since introduction of the TVT procedure in Finland [17]

\begin{tabular}{ll}
\hline Complication & Rate \\
\hline No. of patients: 1,455 & \\
Bladder perforation & $3.7 \%$ \\
Urethral lesion & $0.07 \%$ \\
Bleeding $>200 \mathrm{ml}$ & $1.9 \%$ \\
Retropubic hematoma & $1.9 \%$ \\
Vascular injury & $0.07 \%$ \\
Nerve injury & $0.07 \%$ \\
Bowel injury & $0.0 \%$ \\
\hline
\end{tabular}

The follow-up program included in the training called for registering any kind of intra- or postoperative complications and follow-up visits. This prospective program would thus include the learning curve of every single surgeon performing the TVT procedure. The results of this program were published in 2002. It included all 1,455 TVT procedures performed in the country by the end of 1999. Astonishingly low rates of complications were found, the rate of bladder injury for instance being only $3.8 \%$ [17] (Table 2).

The TVT procedure, being the first minimally invasive surgical operation relying on the mid-urethra theory and utilizing a type 1 synthetic mesh as the tape material, was thoroughly studied and the results were documented before the procedure was offered for common clinical use. The results have furthermore been published in well-renowned peer-reviewed international journals many of them well ahead of launch of the procedure.

Recent history includes the launch and withdrawal of many modifications and copies of the TVT procedure, which shows that any variation of a procedure needs its own thorough clinical testing before it can be accepted for common use. The surprisingly high rates of complications like bladder perforation and postoperative voiding problems seen in more recent reports compared to the rates seen in the initial ones from the Nordic countries emphasizes the need for proper training and adherence to the standardized performance of the operation in order to avoid complications and poorer performance. It is a waste of both public and private resources to launch poorly documented new treatment concepts and it is especially wrong towards the women suffering from stress urinary incontinence to become subjects of experimental efforts without ethical approval and written informed consent.

\section{Conflicts of interest None.}

\section{References}

1. Petros P, Ulmsten U (1990) An integral theory of female urinary incontinence. Experimental and clinical considerations. Acta Obstet Gynecol Scand Suppl 153:7-31 
2. Ingelman-Sundberg A (1957) A vaginal sling operation; for cases of stress incontinence and for women who cannot use a diaphragm due to prolapse of the anterior vaginal wall. J Obstet Gynaecol Br Emp 64:849-851

3. Zacharin RF (1961) Stress incontinence in the absence of prolapse. Med J Aust 1:298

4. Zacharin RF (1963) The suspensory mechanism of the female urethra. J Anat Lond 97:423-427

5. Ulmsten U, Sjöberg NO, Alm P, Andersson KE, Owman C, Walles B (1977) Functional role of an adrenergic sphincter in the female urethra of guinea-pig. Acta Obstet Gynecol Scand 56:387-390

6. Ulmsten U, Asmussen M, Lindström K (1977) A new technique for simultaneous urethrocystometry including measurements of the urethral pressure profile. Urol Int 32:127-136

7. Westby M, Asmussen M, Ulmsten U (1982) Location of maximal intraurethral pressure related to urogenital diaphragm in the female subject as studied by simultaneous urethrocystometry and voiding urethrocystography. Am J Obstet Gynecol 144:408-412

8. Ulmsten U, Henriksson L, Johnson P, Varhos G (1996) An ambulatory surgical procedure under local anesthesia for treatment of female urinary incontinence. Int Urogynecol J Pelvic Floor Dysfunct 7:81-85

9. Ulmsten U, Falconer C, Johnson P, Jooma M, Lannér L, Nilsson CG, Olsson I (1998) A multicenter study of tension-free vaginal tape (TVT) for surgical treatment of stress urinary incontinence. Int Urogynecol J Pelvic Floor Dysfunct 9:210-213
10. Rezapour M, Ulmsten U (2001) Tension-free vaginal tape (TVT) in women with recurrent stress urinary incontinence- - long-term follow up. Int Urogynecol J Pelvic Floor Dysfunct 12(Suppl 2):S9-S11

11. Rezapour M, Falconer C, Ulmsten U (2001) Tension-free vaginal tape (TVT) in stress incontinent women with intrinsic sphincter deficiency (ISD) - a long-term follow-up. Int Urogynecol J Pelvic Floor Dysfunct 12(Suppl 2):S12-S14

12. Rezapour M, Ulmsten U (2001) Tension-free vaginal tape (TVT) in women with mixed urinary incontinence - a long-term follow-up. Int Urogynecol Pelvic Floor Dysfunct 12(Suppl 2):S15-S18

13. Nilsson CG, Kuuva N, Falconer C, Rezapour M, Ulmsten U (2001) Long-term results of the tension-free vaginal tape (TVT) procedure for surgical treatment of female stress urinary incontinence. Int Urogynecol J Pelvic Floor Dysfunct 12(Suppl 2):S5-S8

14. Olsson I, Kroon U (1999) A three-year prospective evaluation of the tension-free vaginal tape. Gynecol Obstet Invest 48:267-269

15. Ulmsten U, Johnson P, Rezapour M (1999) A three-year follow up of tension free vaginal tape for surgical treatment of female stress urinary incontinence. Br J Obstet Gynaecol 106:345-350

16. Nilsson CG, Palva K, Aarnio R, Morcos E, Falconer C (2013) Seventeen years' follow-up of the tension-free vaginal tape procedure for female stress urinary incontinence. Int Urogynecol J 24: $1265-1269$

17. Kuuva N, Nilsson CG (2002) A nationwide analysis of complications associated with the tension-free vaginal tape (TVT) procedure. Acta Obstet Gynecol Scand 81:72-77 